\title{
Familial aggregation of albuminuria and arterial hypertension in an Aboriginal Australian community and the contribution of variants in ACE and TP53
}

\author{
David L. Duffy ${ }^{1}$, Stephen P. McDonald ${ }^{2}$, Beverley Hayhurst ${ }^{3}$, Sianna Panagiotopoulos ${ }^{4}$, Trudy J. Smith ${ }^{5}$,
} Xing L. Wang ${ }^{6}$, David E. Wilcken ${ }^{7}$, Natalia L. Duarte', John Mathews ${ }^{8}$ and Wendy E. Hoy ${ }^{9,10^{*}}$

\begin{abstract}
Background: Aboriginal Australians are at high risk of cardiovascular, metabolic and renal diseases, resulting in a marked reduction in life expectancy when compared to the rest of the Australian population. This is partly due to recognized environmental and lifestyle risk factors, but a contribution of genetic susceptibility is also likely.

Methods: Using results from a comprehensive survey of one community ( $N=1350$ examined individuals), we have tested for familial aggregation of plasma glucose, arterial blood pressure, albuminuria (measured as urinary albumin to creatinine ratio, UACR) and estimated glomerular filtration rate (eGFR), and quantified the contribution of variation at four candidate genes (ACE; TP53; ENOS3; MTHFR).

Results: In the subsample of 357 individuals with complete genotype and phenotype data we showed that both $\operatorname{UACR}\left(h^{2}=64 \%\right)$ and blood pressure ( $\left.\mathrm{sBP} h^{2}=29 \%, \mathrm{dBP}, \mathrm{h}^{2}=11 \%\right)$ were significantly heritable. The ACE insertiondeletion ( $P=0.0009)$ and TP53 codon72 polymorphisms ( $P=0.003)$ together contributed approximately $15 \%$ of the total heritability of UACR, with an effect of ACE genotype on BP also clearly evident.

Conclusions: While the effects of the ACE insertion-deletion on risk of renal disease (especially in the setting of diabetes) are well recognized, this is only the second study to implicate p53 genotype as a risk factor for albuminuria - the other being an earlier study we performed in a different Aboriginal community (McDonald et al., J Am Soc Nephrol 13: 677-83, 2002). We conclude that there are significant genetic contributions to the high prevalence of chronic diseases observed in this population.
\end{abstract}

Keywords: Albuminuria, Epidemiology, Genetics, Heritability

\section{Background}

Chronic diseases such as diabetes mellitus, hypertension, ischaemic heart disease, and chronic renal failure are far more common among Aboriginal Australians than they are in Australians of European descent [2-5]. This is especially true of Aboriginal communities in the "Top End", the tropical northern part of the Northern Territory. In one community, we have demonstrated that these findings

\footnotetext{
* Correspondence:

${ }^{9}$ Centre for Chronic Disease, The University of Queensland School of

Medicine, Brisbane, Australia

${ }^{10}$ Centre for Chronic Disease, Central Clinical School, Royal Brisbane Hospital,

Queensland 4029, Australia

Full list of author information is available at the end of the article
}

can be explained, at least in part, by the presence of a number of environmental and behavioural risk factors for these diseases. Notably, high rates of childhood Group A streptococcal infection and post-streptococcal glomerulonephritis (up to $28 \%$ of one sample under the age of 30 years [6]) were associated with later development of micro- and macro albuminuria [7, 8]. Obesity, alcohol and tobacco overuse were also commonly present.

However, we were also intrigued by the fact that end stage renal disease and albuminuria seemed to aggregate within particular families in these communities [9], an observation that might reflect segregation of disease genes. A number of risk loci have been characterised in 
other ethnic groups: strikingly, the five-fold difference in incidence of renal diseases between African and European descended populations is largely due to two coding variants in the APOL1 gene [10-13]. Using data from another Aboriginal community we have previously shown that variants in two other much studied genes, the $A C E$ insertion-deletion (indel) and TP53*R72P polymorphisms, are associated with albuminuria and hypertension [1]. $A C E$ encodes angiotensin I converting enzyme, and TP53, the key tumor suppressor protein p53. The latter is involved in regulating responses to DNA damage, whether repair or programmed cell death.

We have a particular interest in albuminuria, as measured by the urinary albumin to creatinine ratio (UACR), as it is easily measured in the field, and is a good predictor not just of subsequent development of end stage renal disease, but also of cardiovascular disease morbidity and mortality in both diabetics and nondiabetics [4, 5, 14-17].

In the present paper, we quantify the effects of these $A C E$ and TP53 gene variants in a much larger Aboriginal Australian sample. Family based analysis is used to compare these effects to those of unmeasured genetic risk factors acting in this population on UACR, arterial blood pressure, and plasma glucose.

\section{Methods}

\section{Study population}

As described elsewhere [2, 4-8], a number of surveys (interviews and clinical examinations) and an intervention program focusing on renal and cardiovascular diseases have been carried out in a remote Aboriginal Australian community living on two islands situated off the coast of the Northern Territory, north of Darwin.

All participants completed a questionnaire recording basic demographic information, family relationships, and medical history. Height, weight and hip and waist circumferences were recorded. BP was measured by a single observer using a mercury sphygmomanometer. Urine and blood were collected for routine biochemical screening. In a subset of individuals with elevated spot plasma glucose levels, a $2 \mathrm{~h}$ oral glucose tolerance test was performed. The protocol was approved by the institutional ethics committee and written informed consent was obtained from all participants.

\section{Laboratory methods}

Urinary albumin and creatinine levels in a spot urine collection were used to calculate the albumin:creatinine ratio (UACR), a measurement known to strongly correlate with $24 \mathrm{~h}$ urinary albumin excretion. Repeat UACR measurements were available for only 63 out of 357 individuals, with a test-retest correlation for log transformed UACR of 0.97. We estimated eGFR from serum creatinine level using the MDRD Study equation. Whole blood
(4 ml) for DNA analysis was collected into EDTA tubes, stored at $4{ }^{\circ} \mathrm{C}$ until DNA extraction. DNA specimens were available for 401 subjects. Genotyping was carried out at 6 polymorphisms in four candidate genes: NOS3 (endothelial nitric oxide synthase; rs2070744, rs1799983, i4 VNTR), TP53 (rs1042522), MTHFR (methylenetetra hydrofolate reductase; rs1801133) and ACE (rs4646994) as previously described [1]. These variants were selected because of previously reported associations with diabetes and diabetic nephropathy, or cardiovascular disease (eg [18-22]), and all were polymorphic in the present population (Additional file 1: Table S1).

\section{Statistical methods}

Standard statistical analyses were carried out using the $\mathrm{R}$ statistical package [23]. The mgcv [24] and SemiPar packages [25] were used to investigate nonlinear covariate effects in penalized spline mixed models (with familyspecific intercepts). The family based variance components analyses were carried out using the Sib-pair program [26], MENDEL 5.7 [27] and WOMBAT [28].

Urinary albumin to creatinine ratio was log transformed for subsequent analyses (logACR). Since 162 individuals had a 2 h OGGT plasma glucose measurement, but 197 a fasting plasma glucose, we have analysed the latter, using a $\log$ transformation. Familial aggregation of quantitative traits such as $\log \mathrm{ACR}$ and systolic (sBP) and diastolic (dBP) blood pressure were carried out using a mixed effects model (variance components model). In this analysis we relate the degree of genetic relationship between individuals to their similarity in phenotypes. The random effects were assumed to be multivariate normally distributed, and this was tested by evaluation of model residuals. We utilized the usual biometrical decomposition [29] of the variance into components due to additive genetic random effects (correlated among family members) and residual environmental effects. The heritability is a commonly quoted summary statistic from this type of analysis, and is the proportion of the phenotypic variance of the trait in this population due to genetic effects. Since we have not modeled household effects, it is not possible to disentangle the effects of household and familial environment from genetic effects, and this should be borne in mind when examining the heritability estimates. Fixed effects of age, weight, height, sex and measured genotype were included in the genetic models.

\section{Results}

Clinical data are available for a total of 1350 individuals from the community, more than $80 \%$ of community members of 5 years of age and over. A subsample of 401 individuals were genotyped, chosen on the basis of their ranges of urine ACR being representative of that of the whole community. Pedigrees were successfully constructed for 357 of these individuals. There were a total 
of 771 pedigree members (including unphenotyped "connecting" individuals), with a mean pedigree size of 5.7 individuals (range 3-43), and the deepest pedigree spanned 5 generations. Slightly more males than females were examined (184 M, $173 \mathrm{~F}$ ), and ages ranged from 18 to 76 years (see Table 1).

The subsample for the genetic analyses did not differ significantly from the complete sample in terms of sex ratio, rates of diabetes, blood pressure or UACR. For example, $40 \%$ of the complete sample aged $40-49$ years were macroalbuminuric (UACR > $33 \mathrm{~g} / \mathrm{mol}$ ) versus $39 \%$ of the familial subsample. This rate can be compared to the overall albuminuria rate of $5 \%$ in the 1.8 million individuals (mean age 48) from 26 general population samples described by Nitsch and coworkers [17].

There were strong correlations between the various different traits (Table 2, Figs. 1, 2 and 3). Unsurprisingly, both $\log \mathrm{ACR}$ and BP were correlated with age. There were significant effects of genotype at the $A C E$ indel and TP53 codon72 polymorphisms on multiple clinically relevant phenotypes (Additional file 1: Table S2). Microalbuminuria (defined as 3.4-33 g/mol) was increased in ACE D/I carriers compared to $\mathrm{I} / \mathrm{I}$ carriers $(\mathrm{RR}=1.4$, and see Fig. 1), and macroalbuminuria (>33 g/mol) even further so $(R R=2.2)$, with $47.5 \%$ of $\mathrm{D} / \mathrm{I}$ carriers macroalbuminuric, but only $21 \%$ of the I/I genotype $(P=0.001)$. The effects of ACE genotype on UACR were most obvious after the age of 30 years (see Fig. 2). The D/I carriers also had higher systolic (130.4 versus 119.2 $\mathrm{mm} \mathrm{Hg}$ ) and diastolic blood pressures (83.3 versus $70.7 \mathrm{~mm} \mathrm{Hg}$ ) than I/I carriers (Fig. 3; Additional file 1: Figure S3 and S4), and were four times more likely to be diabetic (22\% versus 5\%, and see Fig. 4 ).

Estimated glomerular filtration rate (eGFR, available for 335 individuals) was nonlinearly related to $\operatorname{logACR}$, as well as to weight. It did not show any significant relationship to ACE or TP53 genotype.

The multivariate genetic variance components analysis of $\log \mathrm{ACR}$ and $\mathrm{BP}$ using MENDEL found that the correlation between these traits was almost completely genetic in nature, with little evidence of a unique environmental (ie intraindividual nongenetic) correlation (Table 3 ). The heritability of logACR was $64 \%$, while that of sBP $24 \%$ and $\mathrm{dBP}$ only $11 \%$. The multivariate adjusted effects of $A C E$ genotype (D/I versus $\mathrm{I} / \mathrm{I}$ ) were $6.8 \mathrm{~mm}$ $\mathrm{Hg}$ of systolic blood pressure, $8.2 \mathrm{~mm} \mathrm{Hg}$ of diastolic blood pressure, and a 2.7-fold increase of UACR (see Table 4). The effect of the TP53*P72 allele on UACR was approximately half that of the $A C E^{*} \mathrm{D}$ allele: 1.6 -fold. We estimate that approximately $9 \%$ of the genetic variance of $\log A C R$ is due to $A C E$, and $5 \%$ due to TP53. In contrast to this, variance components analyses of both eGFR and serum creatinine levels estimated the heritabilities of those traits as not significantly different from zero.

\section{Discussion}

We have now reported a number of studies involving this Australian Aboriginal community [2, 4-10], documenting much higher rates of diabetes mellitus, arterial hypertension, albuminuria and renal disease than are seen in the general Australian population. In the current work, we confirm the clinical impression that both albuminuria and renal insufficiency seems to aggregate within particular families from this community. Because of the correlation between our measure of albuminuria ( $\log \mathrm{ACR})$ and blood pressure, we have carried out multivariate genetic analyses. These found that $\log \mathrm{ACR}$ was strongly heritable, while BP less so. The correlation between logACR and BP was found to be largely genetic in nature.

We further showed that approximately $14 \%$ of the genetic variances of $\log \mathrm{ACR}$ and of $\mathrm{BP}$ were explained by polymorphisms at two loci, $A C E$ and TP53. A number of studies have implicated the $A C E$ insertion/deletion polymorphism in risk of diabetic nephropathy. Mooyart and coworkers' [30] meta-analysis found 42 studies of ACE, giving an overall odds ratio for diabetic nephropathy of 1.24 (95\% CI 1.12-1.37), for the deletion (D allele), but

Table 1 Descriptive statistics for key phenotypes in individuals with measured UACR

\begin{tabular}{|c|c|c|c|}
\hline Variable & All $(N=357)$ & Males $(N=184)$ & Female $(N=173)$ \\
\hline Median Age (range) & $34.6(18.0-76.4)$ & $32.5(18.0-73.2)$ & $36.5(18.0-76.4)$ \\
\hline Geometric mean UACR (range) & $5.3(0.1-605.8)$ & $6.8(0.2-605.8)$ & $4.3(0.1-466.7)$ \\
\hline Percentage UACR > $33 \mathrm{~g} / \mathrm{mol}$ & $25.5 \%$ & $22.8 \%$ & $28.3 \%$ \\
\hline Median BMI (range) & $22.7(14.2-43.5)$ & $22.1(14.2-39.1)$ & $23.1(14.6-43.5)$ \\
\hline Median serum creatinine & $81.0(69-589)$ & $91(63-589)$ & $69(63-238)$ \\
\hline Percentage smokers & $26.3 \%$ & $21.3 \%$ & $31.7 \%$ \\
\hline Median fasting glucose (range) $N=197$ & $4.7(3.2-18.1)$ & $4.6(3.2-17)$ & $4.8(3.6-18.1)$ \\
\hline Percentage fasting glucose $>5.5$ & $22.8 \%$ & $15.9 \%$ & $31.1 \%$ \\
\hline Median systolic BP (range) $N=347$ & $120.0(84-170)$ & $124(84-170)$ & $114(89-170)$ \\
\hline Median diastolic BP (range) & $72(39-130)$ & $76(42-130)$ & $70(39-112)$ \\
\hline
\end{tabular}


Table 2 Pearson correlations between key phenotypes and covariables (Pairwise $N=327-357$ )

\begin{tabular}{|c|c|c|c|c|c|c|c|c|c|c|}
\hline & Sex & Age & $\mathrm{Ht}$ & Wt & BMI & $\mathrm{Cr}$ & eGFR & ACR & $d B P$ & $\mathrm{sBP}$ \\
\hline Sex & 1.00 & & & & & & & & & \\
\hline Age & -0.12 & 1.00 & & & & & & & & \\
\hline Height & 0.70 & -0.01 & 1.00 & & & & & & & \\
\hline Weight & 0.21 & 0.15 & 0.38 & 1.00 & & & & & & \\
\hline BMI & -0.09 & 0.17 & -0.03 & 0.91 & 1.00 & & & & & \\
\hline Creatinine & 0.32 & 0.14 & 0.26 & 0.31 & 0.21 & 1.00 & & & & \\
\hline eGFR & -0.27 & -0.38 & -0.10 & 0.45 & 0.53 & -0.47 & 1.00 & & & \\
\hline $\log A C R$ & -0.11 & 0.45 & -0.01 & 0.29 & 0.30 & 0.19 & -0.04 & 1.00 & & \\
\hline$d B P$ & 0.19 & 0.32 & 0.25 & 0.43 & 0.35 & 0.32 & -0.07 & 0.42 & 1.00 & \\
\hline sBP & 0.25 & 0.36 & 0.24 & 0.33 & 0.25 & 0.27 & -0.14 & 0.33 & 0.61 & 1.00 \\
\hline
\end{tabular}

Bolding denotes a correlation that is statistically significantly different from zero $(P<0.05)$

comment that the effects are more marked in Asian than European populations. Their point estimates agree well with those from the large Diabetes Control and Complications Trial (DCCT) [31], where the I/I genotype hazard ratio was 0.7 for microalbuminuria and 0.6 for severe nephropathy. The effect sizes in the present study are roughly comparable to the latter (we observed 0.71 and 0.45). Most studies have not found a relationship between ACE genotype and essential hypertension. For example, in a meta-analysis of 46 studies, Staessen and coworkers [32] report that although the ACE D allele clearly increased risk of coronary heart disease and stroke, the effects on blood pressure were not significant. In the present study, the D allele was significantly associated with increased blood pressure, which may reflect the high rates of renal disease in this community.

It is interesting to examine the frequency of the $\mathrm{ACE}$ indel across comparable populations to that in the current study (Table 5). Firstly, the frequency of the deleterious D allele in our sample is similar to that reported from other Australian Aboriginal samples. Secondly, it is less common than in most other world populations, with a suggestion of an African-EuropeanAsian-Australian cline.

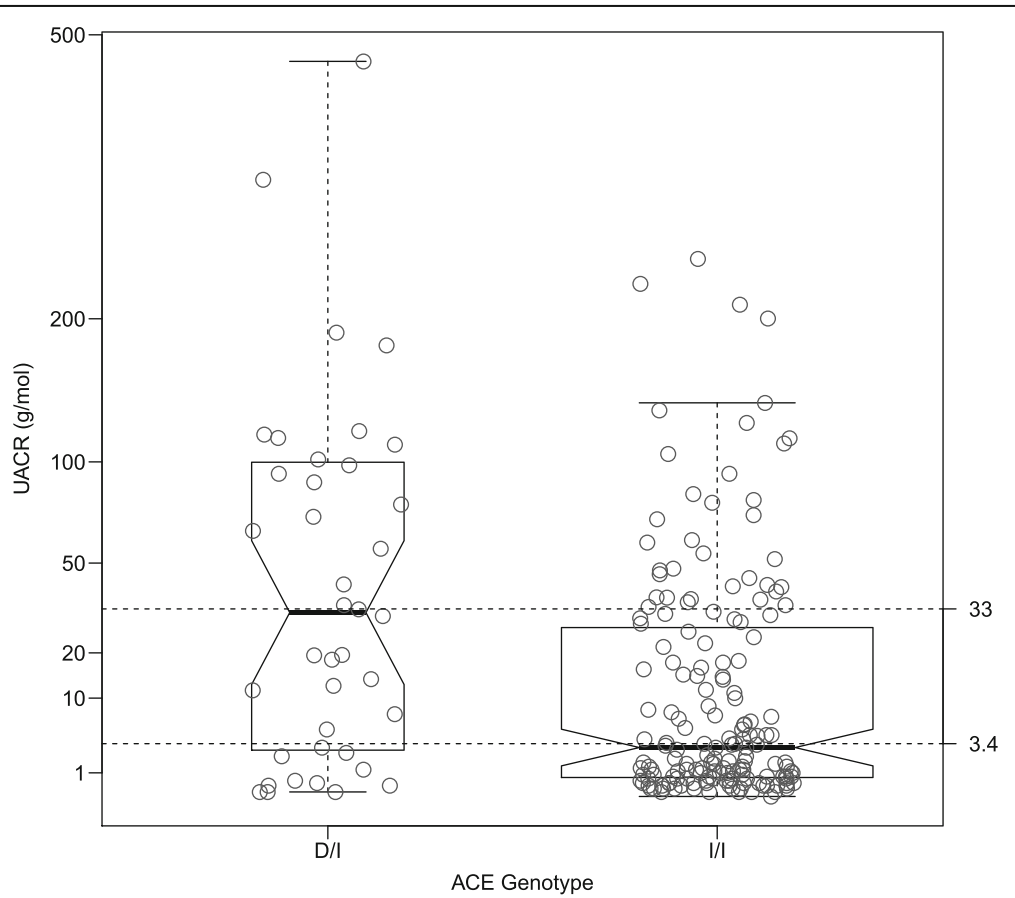

Fig. 1 Urinary albumin:creatinine ratio versus ACE insertion-deletion genotype in a sample of Aboriginal Australians. Lines at UACR of 3.4 and 30 $\mathrm{g} / \mathrm{mol}$ represent suggested diagnostic thresholds for micro- and macroalbuminuria. The notches represent $95 \%$ confidence intervals around the median of each group 


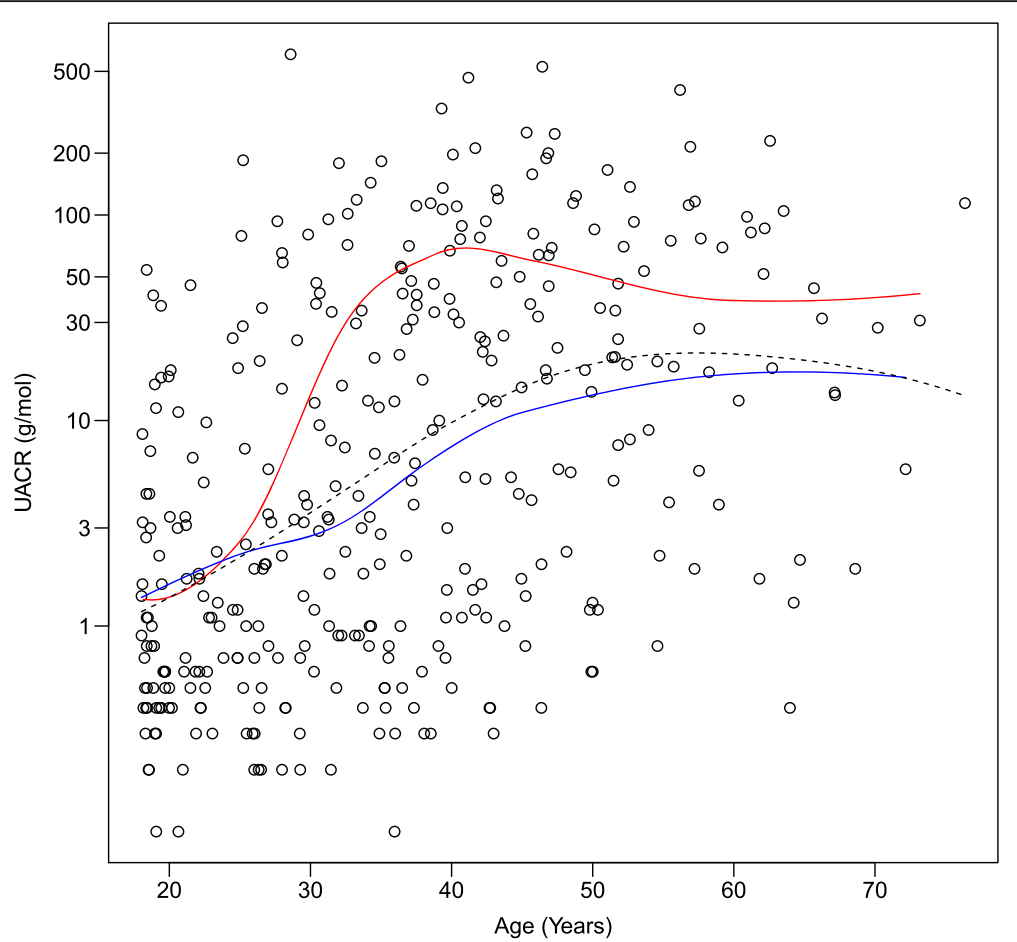

Fig. 2 Effect of ACE insertion-deletion genotype on cross-sectional relationship between age and UACR. Upper curve is D/I genotype group; lower, the I/I genotype group; the dotted line is the overall curve (Flattening of D/I curve after the age of 40 may reflect selective mortality, but there may be other cohort effects acting)

The codon72 TP53 polymorphism has not been commonly studied as a risk factor for renal disease. TP53 is known to be important in acute renal injury via its role in regulation of apoptosis and cell survival, and inhibition of TP53 expression by siRNA reduces the acute kidney injury following administration of aristolochic acid or renal ischemia-reperfusion in animal models, although longer term p53 inhibition may promote renal fibrosis in some species [33, 34]. The Arg72 p53 protein is more pro-apoptotic and tumour suppressive than the Pro72 version [35-37], and in the Hupki humanised mouse model increases rates of obesity and diabetes when fed a high fat diet [38]. In keeping with the latter, Burgdorf and coworkers' metaanalysis of diabetes did find the R72 allele to increase risk of Type 2 diabetes by $6 \%$ [39], though there are no data for diabetic nephropathy per se. A relationship with BP, has also been reported [40], but we do not confirm this. There are large differences in frequency between continental populations, with the ancestral P72 allele common in Africa, and the R72 allele common in European and Asian populations (Table 5). In our study, frequency of the R72 allele was intermediate between Africa and Europe.

In view of the forgoing, this polymorphism is a plausible candidate, and the association found in our earlier study with UACR [1] is replicated here in a second Aboriginal community. That the P72 allele is the risk allele seems counterintuitive, but this may reflect the long term versus short term effect. Because the effect of the R72 allele on human diabetes risk is modest, it is not surprising that we did not detect any association in the present study with plasma glucose levels. Exploration of renal pathology in the humanized $\mathrm{R} 72$ prediabetic mouse model [38] may be of relevance.

For both the $A C E$ and TP53 variants, we should worry that the risk allele is actually a marker for European admixture or ancestry. One example of such ethnic confounding was for diabetes risk in Pima indigenous Americans [41]. Unfortunately, we did not have enough genotyped parentoffspring pairs to carry out a transmission-disequilibrium test (TDT) to definitively exclude this possibility, but point estimates from the TDT (not shown) matched that estimated by the variance components analysis. The observed direction of association is also inconsistent with this type of confounding, in that given the high prevalence of disease in the indigenous community, then European admixture should be protective.

Because we have not used an intrinsically informative design (such as an adoption or twin study), we cannot unequivocally differentiate between effects of other genes and unmeasured shared environmental factors as cause of the observed familial aggregation. One likely familial factor would be infection with, for example, group A streptococci. We did examine other factors such as 


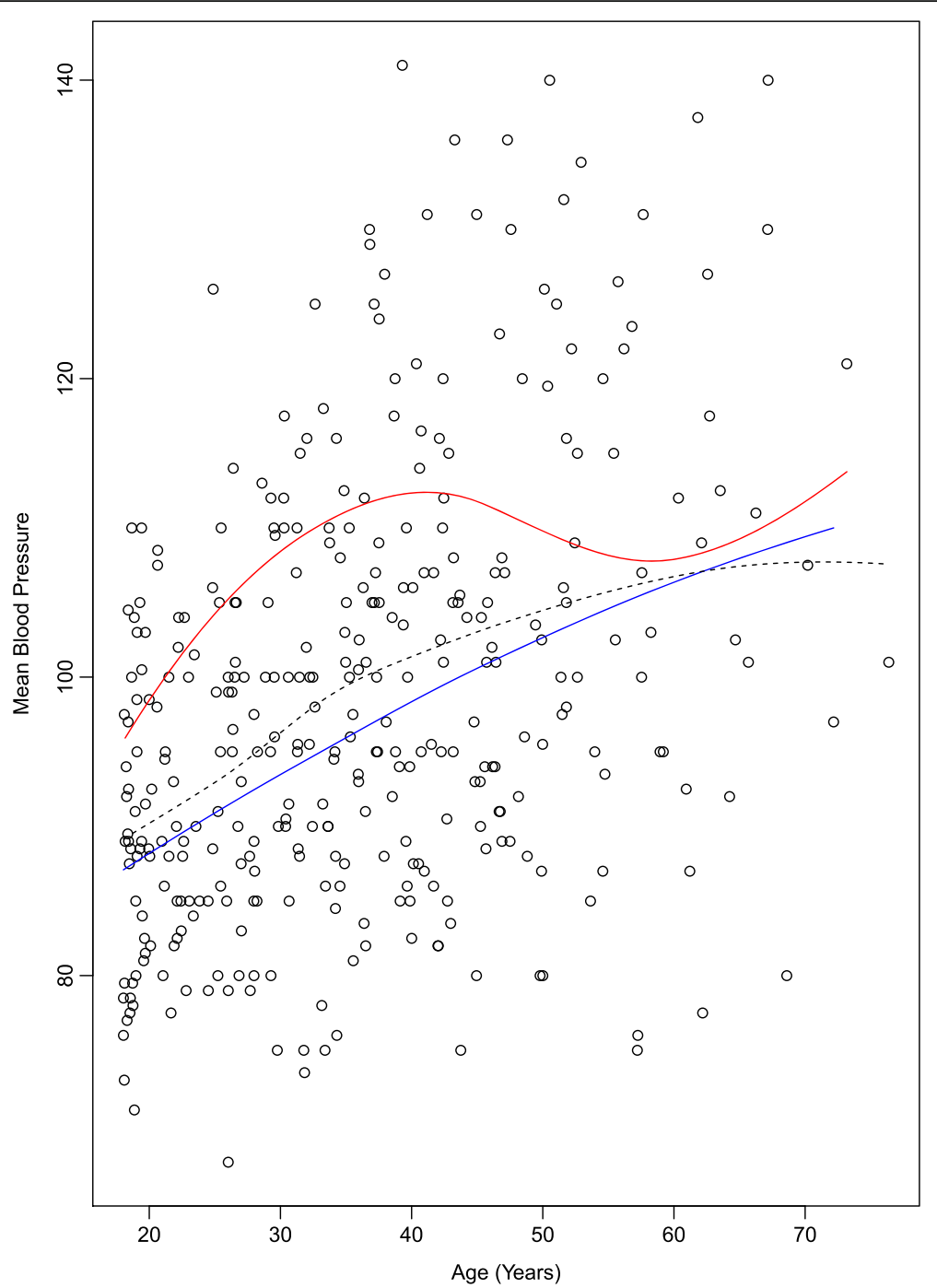

Fig. 3 Effect of ACE insertion-deletion genotype on cross-sectional relationship between age and diastolic blood pressure. Upper curve is D/I genotype group; lower, the I/I genotype group; the dotted line is the overall curve

birth weight (available for a subset of 110 individuals), but these did not aggregate strongly enough within families to act as a confounder [42, 43]. This means we also cannot address whether particular environmental exposures are exacerbating the effects of the candidate gene effects that we have demonstrated, given that the genotypic effect sizes are larger than those seen in other populations.

We found $\log \mathrm{ACR}$ to be a useful choice in comparison to other measures of renal function in terms of the linearity of its relationship with covariates such as age, and found it to be more heritable than covariateadjusted serum creatinine level or glomerular filtration rate. In the present analysis we have used only crosssectional (baseline) data. In previous longitudinal studies in this community, we have shown that $\log \mathrm{ACR}$ is an excellent predictor of change in GFR over time [4]. Aside from this, a number of mortality studies have now shown that albuminuria is a risk predictor independent of glomerular filtration rate [44]. Microalbuminuria occurs both in the context of systemic vascular endothelial dysfunction and in podocyte specific disorders, such as nephrotic syndrome, and so may represent either a common marker or a common pathway for different pathophysiological processes [45].

We have previously presented data showing how UACR increases in this population with age, flattening off by age 60 years (see Fig. 1 from Reference [14]). Fig. 2 in the present paper shows that the same shape relationship occurs for each $A C E$ indel genotype, but that the I/D group rise faster, especially after the age of 30 years, but flattens off by age 45 . This may represent effects of differential mortality or cohort effects - we have reported elsewhere that age-specific mortality rates may be improving in this community with time [46]. 


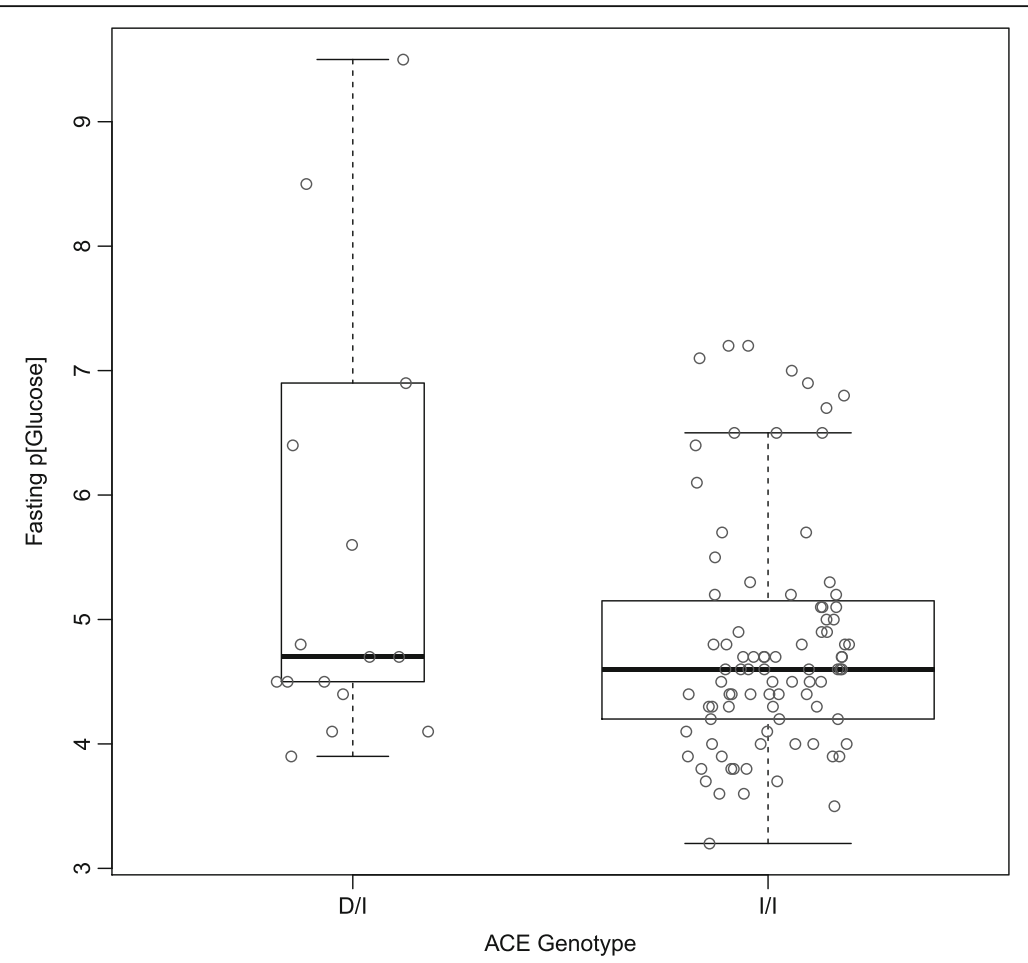

Fig. 4 Effect of ACE insertion-deletion genotype on fasting plasma glucose

Several studies of the genetics of $\log A C R$ have been published that we can compare our results to. These studies have concentrated on families of containing diabetic probands, but a common finding is that the heritability of $\operatorname{logACR}$ is the same in diabetic and nondiabetic family members. Fogarty et al. [47] performed a segregation analysis of UACR in 1269 individuals (630 diabetics) from 96 families, and concluded that there was strong familial aggregation, with a heritability of $0.25(\mathrm{SE}=0.05)$. Langefeld et al. [48] report results from diabetes-concordant sib pair families (662 individuals in 310 families). The heritability of $\log \mathrm{ACR}$ was $0.42(\mathrm{SE}=0.12)$, while that of GFR was 0.75 (0.10). Fox et al. [49] studied logACR in the Framingham families (1055 individuals in 330 families). The heritability of $\log A C R$ was 0.20 . The best linkage peak was lod $=2.22$ on chromosome 8 (D8S1179). Krolewski et al. [50] also performed a genome-wide linkage scan

Table 3 Additive genetic and environmental correlations and heritabilities (main diagonal) from mixed model of BP, logACR, and log transformed fasting plasma glucose (logFPG)

\begin{tabular}{|c|c|c|c|c|c|c|c|c|}
\hline & \multicolumn{4}{|c|}{ Additive Genetic } & \multicolumn{4}{|c|}{ Non-familial Environmental } \\
\hline & SBP & $\mathrm{dBP}$ & $\log A C R$ & $\log F P G$ & sBP & $\mathrm{dBP}$ & $\log A C R$ & $\log F P G$ \\
\hline sBP & 0.26 & & & & 0.74 & & & \\
\hline $\mathrm{dBP}$ & 0.74 & 0.11 & & & 0.47 & 0.88 & & \\
\hline $\log A C R$ & 0.22 & 0.81 & 0.55 & & 0.22 & 0.21 & 0.45 & \\
\hline $\log F P G$ & -0.73 & -0.15 & 0.38 & 0.06 & 0.24 & 0.16 & 0.16 & 0.94 \\
\hline
\end{tabular}

Table 4 Parameter estimates for fixed effects regression part of mixed model for logACR, BP and log fasting plasma glucose

\begin{tabular}{|c|c|c|c|c|}
\hline Trait & Predictor & Estimate & ASE & Wald $P$-value \\
\hline \multirow[t]{5}{*}{$\log A C R$} & Male Sex & -0.114 & 0.0830 & \\
\hline & Age & 0.029 & 0.0030 & \\
\hline & Weight & -0.0007 & 0.0009 & \\
\hline & $A C E^{*} D$ & 0.47 & 0.13 & $0.0003^{* *}$ \\
\hline & TP53*P & 0.20 & 0.074 & $0.007^{* *}$ \\
\hline \multirow[t]{5}{*}{ sBP } & Male Sex & 10.5 & 1.6 & \\
\hline & Age & 0.52 & 0.061 & \\
\hline & Weight & -0.0015 & 0.0017 & \\
\hline & $A C E^{*} D$ & 6.8 & 2.5 & $0.006^{* *}$ \\
\hline & TP53*P & -0.5 & 1.4 & 0.72 \\
\hline \multirow[t]{5}{*}{$\mathrm{dBP}$} & Male Sex & 7.2 & 1.5 & \\
\hline & Age & 0.38 & 0.056 & \\
\hline & Weight & -0.0017 & 0.0016 & \\
\hline & $A C E * D$ & 8.2 & 2.2 & $0.0005^{* *}$ \\
\hline & TP53*P & -0.6 & 1.2 & 0.62 \\
\hline \multirow{5}{*}{$\begin{array}{l}\text { Log Fasting plasma } \\
\text { glucose }\end{array}$} & Male Sex & 0.031 & 0.022 & \\
\hline & Age & 0.0029 & 0.00067 & \\
\hline & Weight & 0.0020 & 0.00053 & \\
\hline & $A C E * D$ & 0.050 & 0.026 & $0.019^{*}$ \\
\hline & TP53*P & 0.0019 & 0.013 & 1.0 \\
\hline
\end{tabular}

* highlights a $P$-value in the range $0.01-0.05$

** highlights a P-value $<0.01$ 
Table 5 Allele frequencies for the ACE insertion-deletion (rs4646994) and TP53 Arg72Pro (rs1042522) polymorphisms in multiple populations

\begin{tabular}{llllll}
\hline & \multicolumn{2}{l}{ ACE } & & & \multicolumn{2}{l}{ TP53 } & \\
\cline { 2 - 3 } Population & $\mathrm{I}$ & $\mathrm{D}$ & & $\mathrm{R}(\mathrm{G})$ & $\mathrm{P}(\mathrm{C})$ \\
\hline Aborigines: This Study & 0.90 & 0.10 & & 0.43 & 0.57 \\
Aborigines: Groote Eylandt & 0.88 & 0.12 & & 0.45 & 0.55 \\
Aborigines: Central Australia & 0.91 & 0.09 & - & - \\
PNG & 0.75 & 0.25 & 0.16 & 0.84 \\
Tamils & 0.69 & 0.31 & & 0.54 & 0.46 \\
UK & 0.49 & 0.51 & 0.69 & 0.31 \\
Yoruba & 0.35 & 0.65 & 0.36 & 0.64 \\
\hline
\end{tabular}

of $\log A C R$ in 63 diabetic families. The heritability of $\log$ ACR was significant in both diabetic $\left(\mathrm{h}^{2}=0.23, P=\right.$ $0.0007)$ and nondiabetic $\left(h^{2}=0.39, P=0.0001\right)$ family members, and the difference in genetic variance between diabetic and nondiabetic relatives was not statistically significant $(P=0.16)$. There was evidence of genetic linkage of $\log \mathrm{ACR}$ to regions on chromosome $22 \mathrm{q}(\operatorname{lod}=3.7)$ and chromosome $7 \mathrm{q}(\operatorname{lod}=3.1)$. In the 59 Caucasian families, an additional locus on $5 q(\operatorname{lod}=3.4)$ also reached significance. Overall, the point estimates of the heritability for $\log A C R$ from these studies are lower than in the present analysis, but within the 95\% confidence interval of our estimate.

More recently, several genome-wide association studies have also been reported for UACR [51-53], as well as eGFR and ESRD [54-57]. Böger and colleagues [52] report a coding variant (rs1801239, I2984V) in the cubilin gene $(C U B N)$ to be significantly associated with UACR. The second best SNP was rs13177732. For idiopathic membranous nephropathy, SNPs in PLA2R1 (rs4664308) and HLA-DQA1 (rs2187668) have been shown to be important in Caucasians, while multiple loci are risk factors for IgA nephropathy in Asians. It should be noted in this context that the dominant pathological findings in the Aboriginal population tend to glomerulomegaly followed by sclerosis [58]. The effects of the high penetrance African pathogenic alleles of APOL1 (rs60910145, rs73885319, rs71785313) are restricted to non-diabetic nephropathies, that is focal segmental glomerulosclerosis, hypertensive end-stage renal disease, IgA nephropathy, HIV-related and lupus nephritis, but the high frequency of these alleles in Africa (37\%) is strongly suspected to be due to Darwinian selection on trypanosomiasis susceptibility [59], a mechanism that will not act in this Australian population. Susceptibility to streptococcal infections may also be a genetic risk factor: mechanistically, Haapasalo et al [60] suggest interactions between bacteria and Complement Factor $\mathrm{H}(\mathrm{CFH})$ affect pathogeneticity, and found that a variant in $\mathrm{CFH}$ (rs1061170, CFH*Y402H) was weakly associated with severe streptococcal disease in European patients (speculatively, we would also highlight that mutations in CFH5 are associated with C3 glomerulonephritis in Cypriots [61], though the mechanism in that condition is unknown). No information on frequency of any of these variants in Australian Aboriginal populations is available at present.

\section{Conclusions}

In conclusion, we have adduced evidence of a significant genetic contribution to variation in risk of albuminuria in this Australian Aboriginal community, of a similar size to that seen in other populations. We demonstrated that two risk loci, the $A C E$ insertion-deletion polymorphisms and the TP53 codon72 each explain comparable proportions of this variance, but that the $A C E \mathrm{D}$ allele, at least, does not explain the high rates of renal dysfunction in this community, given that risk allele frequencies are lower than in other populations. The effect size of the $A C E \mathrm{D}$ allele was, however, slightly greater than that seen elsewhere.

\section{Additional file}

Additional file 1: Supplementary figures and tables. (PDF $88 \mathrm{~kb}$ )

\section{Abbreviations}

ACE: Angiotensin Converting enzyme gene; APOL1: Apolipoprotein L1; BMI: Body mass index; $\mathrm{CFH}$ : Complement factor $\mathrm{H}$; CUBN: Cubulin gene; dBP: diastolic blood pressure; DCCT: Diabetes control and complications trial; eGFR: Estimated glomerular filtration rate; ESRD: End stage renal disease; lod: Decimal log odds ratio; logACR: Log-transformed urinary albumin to creatinine ratio; MTHFR: methylenetetrahydrofolate reductase gene; NOS3: Endothelial nitric oxide synthase gene; OGGT: Oral glucose tolerance test; P72: Proline at amino acid position 72 of a peptide; sBP: Systolic blood pressure; TDT: Transmission disequilibrium test; TP53: Tumour protein p53 gene; UACR: Urinary albumin to creatinine Ratio; VNTR: Variable number tandem repeat polymorphism

\section{Acknowledgements}

Not applicable.

\section{Funding}

DLD was an NHMRC Senior Research Fellow. WH holds an Australia Fellowship. This study was supported by multiple organisations: NHMRC Project grant: Epidemiology and prevention of renal disease in Australian Aborigines - Part 1, APP921134. NHMRC Project grant: Family studies of renal disease, social, environmental and genetic causes, APP951250.NHMRC Project grant and Senior Research Fellowship: Epidemiology and prevention of renal disease in Australian Aborigines - Part 2, APP951342. The Colonial Foundation, Australia. NHMRC Australia Research Fellowship: Chronic Disease in High Risk Populations, APP511081. NHMRC Centre of Research Excellence: CRE in Chronic Kidney Disease in Australia, CKD.CRE, APP1079502. Funding bodies made no contributions to the design, collection, analysis, interpretation of data, writing of the manuscript and submission of the manuscript for publication.

\section{Availability of data and materials}

The data supporting the main conclusions are shown in detailed scattered plots in the figures. Pedigrees and individual genotype and phenotype data are not publicly available given the sensitivities of the indigenous community involved, but are available from the corresponding author on reasonable request. 


\section{Authors' contributions}

DLD wrote the manuscript and carried out the genetic analyses. WH and JM conceived the study, and ran the field phase, the latter with BH. SM, SP, TS, XW, DW, ND carried out biochemical analyses and genotyping. All authors read and approved the final manuscript.

\section{Competing interests}

The authors declare that they have no competing interests.

\section{Ethics approval and consent to participate}

The protocol was approved by the Human Research Ethics Committee of Territory Health Services and Menzies School of Health Research (HREC ID No 94/26). Written informed consent was obtained from all participants.

\section{Author details}

'Genetic Epidemiology Laboratory, QIMR Berghofer Institute of Medical Research, 300 Herston Rd, Brisbane 4006, Australia. ${ }^{2}$ The Queen Elizabeth Hospital, Adelaide, Australia. ${ }^{3}$ Cradle Coast Authority, Tasmania, Formerly Menzies School of Health Research, Darwin, Australia. ${ }^{4}$ Department of Medicine, University of Melbourne, Melbourne, Australia. ${ }^{5}$ Menzies School of Health Research, Darwin, Australia. ${ }^{6}$ Department of Genetics, Southwest Foundation for Biomedical Research, San Antonio, Texas, Australia.

${ }^{7}$ Cardiovascular Genetics Department, Prince of Wales Hospital, Sydney, Australia. ${ }^{8}$ Melbourne School of Population and Global Health, University of Melbourne, Melbourne, Australia. ${ }^{9}$ Centre for Chronic Disease, The University of Queensland School of Medicine, Brisbane, Australia. ${ }^{10}$ Centre for Chronic Disease, Central Clinical School, Royal Brisbane Hospital, Queensland 4029, Australia.

\section{Received: 1 November 2015 Accepted: 9 November 2016}

\section{Published online: 21 November 2016}

\section{References}

1. McDonald SP, Hoy WE, Maguire GP, Duarte NL, Wilcken DEL, Wang XL. The p53Pro72Arg polymorphism is associated with albuminuria among aboriginal Australians. J Am Soc Nephrol. 2002:13:677-83.

2. Hoy WE, Kondalsamy-Chennakesavan S, Wang Z, et al. Quantifying the excess risk for proteinuria, hypertension and diabetes in Australian Aborigines: comparison of profiles in three remote communities in the Northern Territory with those in the AusDiab study. Aust N Z J Public Health. 2007:31:177-83.

3. AlHW. Australian Burden of Disease Study: impact and causes of illness and death in Aboriginal and Torres Strait Islander people 2011. Australian Burden of Disease Study series no. 6. Cat. no. BOD 7. Canberra: AlHW; 2016.

4. Hoy WE, Wang Z, VanBuynder P, Baker PR, Mathews JD. The natural history of renal disease in Australian Aborigines. Part 1. Changes in albuminuria and glomerular filtration rate over time. Kidney Int. 2001:60:243-8.

5. Hoy WE, Wang Z, VanBuynder P, Baker PR, McDonald SM, Mathews JD. The natural history of renal disease in Australian Aborigines. Part 2. Albuminuria predicts natural death and renal failure. Kidney Int. 2001;60:249-56.

6. Hoy WE, Mathews JD, McCredie DA, et al. The multidimensional nature of renal disease: rates and associations of albuminuria in an Australian Aboriginal community. Kidney Int. 1998;54:1296-304.

7. White AV Hoy WE, McCredie DA. Childhood post-streptococcal glomerulonephritis as a risk factor for chronic renal disease in later life. Med J Aust. 2001;174:492-6.

8. Hoy WE, White AV, Dowling A, et al. Post-streptococcal glomerulonephritis is a strong risk factor for chronic kidney disease in later life. Kidney Int. 2012;81:1026-32.

9. Hoy WE, Rees $M$, Kile E, et al. Low birthweight and renal disease in Australian aborigines. Lancet. 1998;352:1826-7.

10. Genovese G, Tonna SJ, Knob AU, et al. A risk allele for focal segmental glomerulosclerosis in African Americans is located within a region containing APOL1 and MYH9. Kidney Int. 2010;78:698-704.

11. Kopp JB, Nelson GW, Sampath K, et al. APOL1 genetic variants in focal segmental glomerulosclerosis and HIV-associated nephropathy. J Am Soc Nephrol. 2011:22:2129-37.

12. Freedman BI, Langefeld CD, Turner J, et al. Association of APOL1 variants with mild kidney disease in the first-degree relatives of African American patients with non-diabetic end-stage renal disease. Kidney Int. 2012;82:805-11.
13. Lipkowitz MS, Freedman BI, Langefeld CD, et al. Apolipoprotein L1 gene variants associate with hypertension-attributed nephropathy and the rate of kidney function decline in African Americans. Kidney Int. 2013;83:114-20.

14. Hoy W, McDonald SP. Albuminuria: marker or target in indigenous populations. Kidney Int Suppl. 2004;66:S25-S31.

15. Arnlöv J, Evans JC, Meigs JB, et al. Low-grade albuminuria and incidence of cardiovascular disease events in nonhypertensive and nondiabetic individuals: the Framingham Heart Study. Circulation. 2005;1 12:969-75.

16. Chronic Kidney Disease Prognosis Consortium, Matsushita K, van der Velde $\mathrm{M}$, et al. Association of estimated glomerular filtration rate and albuminuria with all-cause and cardiovascular mortality in general population cohorts: a collaborative meta-analysis. Lancet. 2010;375:2073-81.

17. Nitsch D, Grams M, Sang Y, et al. Associations of estimated glomerular filtration rate and albuminuria with mortality and renal failure by sex: a meta-analysis. BMJ. 2013;346:f324.

18. Liu Y, Burdon KP, Langefeld CD, Beck SR, Wagenknecht LE, Rich SS, Bowden DW. Freedman BI. T-786C polymorphism of the endothelial nitric oxide synthase gene is associated with albuminuria in the diabetes heart study. J Am Soc Nephrol. 2005:16:1085-90.

19. Möllsten A, Wessman M, Svensson M, Forsblom C, Parkkonen M, Brismar K, Groop PH, Dahlquist G. Glu298Asp and NOS4ab polymorphisms in diabetic nephropathy. Ann Med. 2006;38:522-8.

20. Neugebauer S, Baba T, Watanabe T. Methylenetetrahydrofolate reductase gene polymorphism as a risk factor for diabetic nephropathy in NIDDM patients. Lancet. 1998;352:454.

21. Niu W, Yue Q. An updated meta-analysis of methylenetetrahydrofolate reductase gene $677 C / T$ polymorphism with diabetic nephropathy and diabetic retinopathy. Diab Res Clin Pract. 2012;95:110-8.

22. Wirta V, Huang XH, Wirta O, Rantalaiho V, Pasternack A, Jokela H, Koivula T, Lehtimäki T. Mutation C677T of methylenetetrahydrofolate reductase gene is not associated with coronary artery disease, but possibly with albuminuria, in type 2 diabetic patients. Clin Chem Lab Med. 1998;36:625-8.

23. R Core Team. R: A language and environment for statistical computing. R Foundation for Statistical Computing, Vienna, Austria. URL https://www.R-project.org/. Accessed 11 Nov 2016.

24. Wood SN. Stable and efficient multiple smoothing parameter estimation for generalized additive models. J Am Stat Assoc. 2004;99:673-86.

25. Wand M. SemiPar: Semiparametic Regression. 2013.

26. Duffy DL. Sib-pair [Computer Program]. 2006.

27. Lange K, Cantor R, Perola M, Sabatti C, Sinsheimer J, Sobel E. MENDEL Version 4.0: A complete package for the exact genetic analysis of discrete traits in pedigrees and population data sets. Am J Hum Genet. 2001;69(Supp):A1886.

28. Meyer K. WOMBAT - A tool for mixed model analyses in quantitative genetics by REML. J Zhejiang Uni Science B. 2007;8:815-21.

29. Hopper JL. Variance components for statistical genetics: applications in medical research to characteristics related to human diseases and health. Stat Methods Med Res. 1993:2:199-223.

30. Mooyaart AL, Valk EJJ, van Es LA, et al. Genetic associations in diabetic nephropathy: a meta-analysis. Diabetologia. 2011;54:544-53.

31. Boright AP, Paterson AD, Mirea $L$, et al. Genetic variation at the ACE gene is associated with persistent microalbuminuria and severe nephropathy in type 1 diabetes: the DCCT/EDIC Genetics Study. Diabetes. 2005;54:1238-44.

32. Staessen JA, Wang JG, Ginocchio G, et al. The deletion/insertion polymorphism of the angiotensin converting enzyme gene and cardiovascular-renal risk. J Hypertens. 1997:15:1579-92.

33. Sutton TA, Hato T, Mai E, Yoshimoto M, Kuehl S, Anderson M, Mang H, Plotkin Z, Chan RJ, Dagher PC. p53 is renoprotective after ischemic kidney injury by reducing inflammation. J Am Soc Nephrol. 2013;24:113-24.

34. Ying Y, Kim J, Westphal SN, Long KE, Padanilam BJ. Targeted deletion of p53 in the proximal tubule prevents ischemic renal injury. J Am Soc Nephrol. 2014;25:2707-16.

35. Dumont P, Leu JI-J, Della Pietra AC, George DL, Murphy M. The codon 72 polymorphic variants of p53 have markedly different apoptotic potential. Nat Genet. 2003:33:357-65.

36. Zhu F, Dollé MET, Berton TR, Kuiper RV, Capps C, Espejo A, McArthur MJ, Bedford MT, van Steeg $\mathrm{H}$, de Vries A, Johnson DG. Mouse models for the p53 R72P polymorphism mimic human phenotypes. Cancer Res. 2010;70:5851-9.

37. Gomez-Sanchez JC, Delgado-Esteban M, Rodriquez-Hernandez I, Sobrino T, Perez de la Ossa N, Reverte S, Bolaños JP, Gonzalez-Sarmiento R, Castillo J, Almeida A. The human Tp53 Arg72Pro polymorphism explains different functional prognosis in stroke. J Exp Med. 2011;208:429-37. 
38. Kung CP, Leu Jl, Basu S, Khaku S, Anokye-Danso F, Liu Q, George DL, Ahima RS, Murphy ME. The P72R Polymorphism of p53 Predisposes to Obesity and Metabolic Dysfunction. Cell Rep. 2016;14:2413-25.

39. Burgdorf KS, Grarup N, Justesen JM, Harder MN, Witte DR, Jørgensen T, Sandbæk A, Lauritzen T, Madsbad S, Hansen T, Pedersen O, DIAGRAMC. Studies of the association of Arg72Pro of tumor suppressor protein p53 with type 2 diabetes in a combined analysis of 55,521 Europeans. PLoS One. 2011;6:e15813.

40. Reiling E, Lyssenko V, Boer JM, et al. Codon 72 polymorphism (rs1042522) of TP53 is associated with changes in diastolic blood pressure over time. Eur J Hum Genet. 2012;20:696-70.

41. Knowler WC, Williams RC, Pettitt DJ, Steinberg AG. Gm3;5,13,14 and type 2 diabetes mellitus: an association in American Indians with genetic admixture. Am J Hum Genet. 1988;43:520-6.

42. Aalen $\mathrm{OO}$. Modelling the influence of risk factors on familial aggregation of disease Biometrics 1991;47(3):933-45

43. Hopper JL, Carlin JB. Familial aggregation of a disease consequent upon correlation between relatives in a risk factor measured on a continuous scale. Am J Epidemiol. 1992;136:1138-47.

44. Waheed S, Matsushita K, Astor BC, Hoogeveen RC, Ballantyne C, Coresh J. Combined association of creatinine, albuminuria, and cystatin $C$ with allcause mortality and cardiovascular and kidney outcomes. Clin J Am Soc Nephrol. 2013;8:434-42.

45. Satchell S. The role of the glomerular endothelium in albumin handling. Nat Rev Nephrol. 2013;9:717-25.

46. Wang Z, Hoy WE. Decreasing rates of natural deaths in a remote Australian Aboriginal community, 1996-2010. Aust N Z J Public Health. 2013;37:365-70.

47. Fogarty DG, Hanna LS, Wantman M, Warram JH, Krolewski AS, Rich SS. Segregation analysis of urinary albumin excretion in families with type 2 diabetes. Diabetes. 2000;49:1057-63.

48. Langefeld CD, Beck SR, Bowden DW, Rich SS, Wagenknecht LE, Freedman BI. Heritability of GFR and albuminuria in Caucasians with type 2 diabetes mellitus. Am J Kidney Dis. 2004;43:796-800.

49. Fox CS, Yang Q, Guo C-Y, et al. Genome-wide linkage analysis to urinary microalbuminuria in a community-based sample: the Framingham Heart Study. Kidney Int. 2005;67:70-4.

50. Krolewski AS, Poznik GD, Placha G, et al. A genome-wide linkage scan for genes controlling variation in urinary albumin excretion in type II diabetes. Kidney Int. 2006;69:129-36.

51. Hwang S-J, Yang Q, Meigs JB, Pearce EN, Fox CS. A genome-wide association for kidney function and endocrine-related traits in the NHLBl's Framingham Heart Study. BMC Med Genet. 2007;8 Suppl 1:S10.

52. Böger $\mathrm{CA}$, Chen $\mathrm{M}-\mathrm{H}$, Tin $\mathrm{A}$, et al. CUBN is a gene locus for albuminuria. J Am Soc Nephrol. 2011;22:555-70.

53. Liu C-T, Garnaas MK, Tin A, et al. Genetic association for renal traits among participants of African ancestry reveals new loci for renal function. PLoS Genet. 2011;7:e1002264.

54. Chambers JC, Zhang W, Lord GM, et al. Genetic loci influencing kidney function and chronic kidney disease. Nat Genet. 2010;42:373-5.

55. Köttgen A, Pattaro C, Böger CA, et al. New loci associated with kidney function and chronic kidney disease. Nat Genet. 2010;42:376-84.

56. McDonough CW, Palmer ND, Hicks PJ, et al. A genome-wide association study for diabetic nephropathy genes in African Americans. Kidney Int. 2011;79:563-72.

57. Pattaro C, Köttgen A, Teumer A, et al. Genome-wide association and functional follow-up reveals new loci for kidney function. PLoS Genet. 2012;8:e1002584

58. Young RJ, Hoy WE, Kincaid-Smith P, Seymour AE, Bertram JF. Glomerular size and glomerulosclerosis in Australian aborigines. Am J Kidney Dis. 2000;36:481-9.

59. Genovese G, Friedman DJ, Ross MD, et al. Association of trypanolytic ApoL1 variants with kidney disease in African Americans. Science. 2010;329:841-5.

60. Haapasalo K, Vuopio J, Syrjänen J, et al. Acquisition of complement factor $\mathrm{H}$ is important for pathogenesis of Streptococcus pyogenes infections: evidence from bacterial in vitro survival and human genetic association. J Immunol. 2012;188:426-35.

61. Gale DP, de Jorge EG, Cook HT, et al. Identification of a mutation in complement factor H-related protein 5 in patients of Cypriot origin with glomerulonephritis. Lancet. 2010;376:794-801.

\section{Submit your next manuscript to BioMed Central and we will help you at every step:}

- We accept pre-submission inquiries

- Our selector tool helps you to find the most relevant journal

- We provide round the clock customer support

- Convenient online submission

- Thorough peer review

- Inclusion in PubMed and all major indexing services

- Maximum visibility for your research

Submit your manuscript at www.biomedcentral.com/submit

) Biomed Central 